\title{
La petición en Francia en el siglo XVIII y las peticiones modernas: aprendiendo de una conexión histórica incongruente ${ }^{1}$
}

Jean-Gabriel CONTAMIN

¿A caso es sociológicamente pertinente intentar estudiar una forma de acción pública ciudadana, como lo es la petición, a pesar de los múltiples rostros que ésta pueda adoptar? ¿Hay algo en común entre una petición de "intelectuales" y una petición de "ciudadanos", entre los usos de la forma peticionaria hoy en día y aquellos de los cuales pudo ser objeto cuando el sufragio universal, la televisión o las encuestas no existían? ¿Acaso la permanencia de la denominación es suficiente para justificar que se estudie, en sí, un objeto que ha sido ungido por numerosas causas, por múltiples grupos, bajo diversas modalidades, en contextos históricos, políticos, institucionales, geográficos distintos?

A estas interrogantes, que están al centro de una de las principales maneras de pensar las movilizaciones colectivas, aquella de los "tipos de acción" (Tilly, 1978: 8-9), Michel Offerlé, trabajando sobre la manifestación, pareciera responder por la negativa. De un siglo a otro, adelanta el autor, "las palabras no designan las mismas cosas, las tecnologías de construcción y de expresión colectiva del descontento no son las mismas, ni en su forma, ni en las relaciones que mantienen entre ellas" (Offerlé, 1990: 94). Así como se ha recurrido a la historia para estudiar el desempleo, el Estado o el voto, to-

1. Una primera versión de este artículo fue publicada en un libro colectivo bajo la dirección de Pascale Laborier y Danny Trom en Francia en el año 2003: Historicités de l'action publique, PUF/CURAPP. Texto traducido por Carolina Gutiérrez Ruiz y Daniela Cuadros Garland. 
mando en cuenta la diversidad de los fenómenos y sus formas de objetivación jurídicas, administrativas o estadísticas, quisiéramos mostrar cómo es que formas de acción ciudadana poco objetivadas como la petición escrita, también tienen una realidad sociológica trans-histórica.

Los diversos usos históricos de la petición escrita -definida como un "texto reivindicativo redactado para ser suscrito por varios individuos, entre los cuales algunos no pudieron participar en su concepción"- responden a una lógica lo suficientemente similar como para que tenga sentido analizarlos juntos. Se intentará ilustrar aquí la fecundidad heurística del giro por la historia, su capacidad para aclarar ciertos aspectos que podrían permanecer invisibles en una perspectiva sincrónica. Ello a través del establecimiento de una conexión incongruente y científicamente "incorrecta" -particularmente según las normas de la disciplina histórica- como lo es el análisis comparativo de argumentos que fueron utilizados contra lo que constituye uno de los primeros usos modernos de la forma peticionaria en Francia (la Petición de ciudadanos domiciliados en París o petición Guillotin, lanzada en 1788) y de argumentos opuestos contra quienes recurren a la petición en la actualidad ${ }^{2}$. Se trata de mostrar el interés de la evolución histórica de los cuadros de deslegitimación política de la petición escrita para el estudio de esta forma de acción.

Aun cuando un decreto del Consejo del 21 de junio de 1717 prohibía a toda persona firmar cualquier acto o petición sin la autorización del rey, el artículo VIII del decreto del Consejo de Estado del Rey del 5 de julio de 1788 sobre la convocatoria a los Estados Generales del Reino permitió, por primera vez en Francia, la impresión y difusión de Tesis sobre la historia y la política sin que tuvieran que ser previamente sometidas a la censura ni a la autorización policial: el Rey invita a "todos los sabios y personas instruidas de su reino (...) a enviar al señor Ministro de Justicia todas las informaciones y tesis" relativas a la convocatoria de los Estados Generales ${ }^{3}$. A partir de entonces se multiplicaron las ediciones polémicas, mayoritariamente anónimas. Ahora bien, existe entre esos opúsculos un texto que determina, no tanto por su contenido sino por su forma y, sobre todo, por su modo de difusión, lo que es una "Petición". La "Petición de ciudadanos domiciliados en París" 4 pide, tal como lo habían hecho antes las tres órdenes del Delfinado en el Castillo de Vizille (resoluciones del 20/7/1788), que la representación del Tercer Estado en los Estados Generales sea al menos igual a la del conjunto de las dos otras órdenes, que los votos sean contados por cabeza y que los diputados del Tercer Estado sean exclusivamente elegidos dentro de esa Orden. No se trata de una instancia,

2. Inspirándonos de T. Gitlin (1980: 27sq.) nos referiremos a esas estrategias argumentativas como a "cuadros de deslegitimación política" de la petición.

3. Para una representación del conjunto de esos eventos, véase Chassin, 1888.

4. Esta petición fue llamada de diferentes maneras, también aparece en los textos estudiados como la "Petición del doctor Guillotin" o la "Petición de los burgueses parisinos". Estas expresiones se utilizarán indistintamente dado que son impropias y que son a la vez un medio para legitimar o estigmatizar la acción. 
de una súplica, de una tesis o de un memorial, sino de una "Petición" caracterizada por la decisión de sus promotores que ejemplares fueran firmados por particulares en los bufetes de los notarios de París. Así entonces, en este texto se encuentran los dos rasgos característicos de la definición "moderna" de la petición: se trata de un texto reivindicativo destinado a ser suscrito por varios individuos, entre los cuales efectivamente algunos no pudieron participar en su concepción.

Se podría ver, en la iniciativa de la Petición Guillotin, el "primer" uso moderno en Francia de una práctica que ya era ampliamente conocida en Gran Bretaña (Zaret, 1996). Esta sería "la primera vez en la historia de Francia en que los súbditos presentaban una petición al Rey" (Soubiran, 1962: 106). Esta afirmación podría ser la oportunidad para formular una doble interrogación. Primero, ¿cómo es que la petición, como forma de acción colectiva, pudo ser importada de Gran Bretaña a Francia? Segundo, en cuanto al uso de herramientas conceptuales elaboradas a partir del análisis de situaciones contemporáneas y su posibilidad de entregar nuevos elementos para la comprensión del pasado: ¿puede, por ejemplo, el modelo de difusión internacional de repertorios de protesta, propuesto por D. McAdam y D. Rucht (1993), ser aplicado a un contexto donde las libertades públicas, los medios de comunicación y las posibilidades de circulación eran limitados?

En una perspectiva como ésa se podría haber insistido en la importancia de Joseph-Ignace Guillotin en el proceso de importación de la petición en Francia (ese "buen doctor" cuyo nombre trascendió, muy a pesar suyo, junto con una máquina que no habría ambicionado por sí solo). Se podría haber insistido en las características de la trayectoria de este personaje, aquellas que pudieron predisponerlo a asumir el doble rol de "cadena de difusión" y de "adaptador", en los términos de McAdam y D. Rucht. Se habría podido analizar asimismo aquello que en la cultura política de fines del siglo XVIII hizo posible la importación de la petición en Francia ${ }^{5}$. Sin embargo, una investigación de ese tipo supondría una forma de exploración de los orígenes del peticionismo o un fetichismo sobre su datación de origen, cuya pertinencia y fecundidad son fuertemente cuestionables (Offerlé, 1990).

No es el carácter "objetivamente" insólito lo que le confiere su interés al episodio de la "Petición del Doctor Guillotin": así como la guillotina, la "invención" de la petición en Francia no es atribuible al buen doctor Guillotin. Al contrario, el análisis de esta petición puede ser fecundo según tres argumentos. Primero, sin lugar a dudas el episodio no es totalmente inédito, aunque surge en un período cuando la petición escrita no se ha vuelto aún una práctica rutinaria y aun cuando se pueda expresar explícitamente en ella un conjunto de representaciones que luego serían incluidas (con mayor facilidad) en la categoría de "aquello que está implícito" en una petición. Segundo, esta petición favorece cierto 
tipo de difusión y ocasiona reacciones que constituyen elementos para comprender lo que, desde la mirada de los actores, en esta configuración precisa, una petición puede ser o no ser. De hecho, un conjunto de indicios permiten pensar que el texto recibió una acogida extraordinaria. La petición recibió el apoyo de los Seis Cuerpos de Mercaderes de París, es decir, de las corporaciones de comercio parisino más ricas, las cuales hacen suya la petición redactada por Guillotin. Y, en el mismo momento en que el Parlamento de París condenaba su difusión, el número y diversidad de firmas que vienen a apoyar al texto es notable ${ }^{6}$; así como lo es la popularidad que parece beneficiar a partir de entonces al doctor Guillotin, quien será luego, por ejemplo, elegido diputado de París. Por último y probablemente más importante aún, surgen diferentes discursos sobre esta petición. Numerosos folletos aparecen para apoyarla o para oponerse a ella. Esta petición es incluso objeto de un proceso en el Parlamento de París. Se trata por lo tanto de reacciones diversas -folletos, alegatos, testimonios de actores descubiertos en falta, veredictosque, vistas a través de las miradas de los actores, para el investigador constituyen medios de identificación de las normas a las cuales la acción peticionaria estaría llamada a obedecer y de los ángulos de ataque por los cuales ésta sería particularmente vulnerable.

Para efectos del presente análisis se utilizarán, en particular ${ }^{7}$, cuatro textos que atacan a la petición Guillotin desde puntos de vista y en contextos de enunciación diferentes: el acta de acusación en sí mismo, la crítica jurídica, una crítica "parlamentaria" que explicita esta novedad en el espacio público, emplazándose desde el punto de vista de las autoridades (Sobre la petición propuesta a los parisinos) ${ }^{8}$, una crítica "plebeya" en donde el autor se posiciona como defensor de los campesinos (Bill de los habitantes de Bagnolet, Charonne y otros lugares, reunidos en asamblea) $)^{9}$ y una crítica "aristocrática" cuyo representante es más bien partidario de la Nobleza (el Discípulo de Montesquieu a los señores diputados de los Estados Generales... $)^{10}$.

Pero por muy importante que la petición Guillotin haya sido en su época, el análisis de esta controversia no aportaría muchas enseñanzas a quien deseara estudiar la petición escrita hoy en día, si se demostrase que el conjunto de los cuadros de deslegitimación entonces utilizados en contra de las peticiones escritas fuera únicamente vinculable a la configuración política e histórica en la cual ese conflicto fue originado. Es decir, el análisis de la petición Guillotin no tendría mucho interés para

6. Según Soubiran se trata de "miles" de firmas que provienen del "conjunto de los burgueses parisinos" (Soubiran, 1962: 109-110).

7. La lista del conjunto de folletos utilizados en el marco de este trabajo se encuentra en anexo a continuación.

8. Sur la Pétition proposée aux Parisiens. 1789. s.l.n.d., BN-Lb39-848.

9. Bill des habitants de Bagnolet, Charonne et autres lieux, pour servir de suite à la Pétition des six corps. 1788. s.l.n.d., BN- Lb39-695.

10. Disciple de Montesquieu à MM. les députés aux Etats-Généraux ou Supplémentà la pétition des bourgeois de Paris... 1789. s.l.n.d., BN-Lb39-1384. 
nosotros si la controversia sólo pudiera ser pensada como un objeto particular, en una situación específica de ampliación subjetiva de la "estructura de oportunidades políticas" (Kitschelt, 1986) que pesa sobre los argumentos a los cuales cada uno puede recurrir en su momento. Sin embargo, en última instancia lo que fundamenta la fecundidad heurística de este caso es el hecho que, contra toda expectativa, los cuadros de deslegitimación utilizados en oposición a la petición Guillotin en un contexto histórico, institucional, ideológico y político preciso, se asemejan en muchos aspectos a lo que, por otra parte, se ha podido identificar estudiando peticiones contemporáneas iniciadas en contextos y por causas absolutamente diferentes (Contamin, 2001).

Por lo tanto, se quisiera exponer aquí el aprendizaje que se puede desprender de este acercamiento histórico incongruente, entre la petición Guillotin y peticiones modernas, para el estudio de la petición escrita hoy en día. Se trata de demostrar, en la práctica, la fecundidad de un giro por la historia para una investigación en ciencia política interesada, ante todo, en el presente. Importa entonces mostrar en qué medida el hecho de recurrir a la historia puede ser fuente de cuestionamientos o de sorpresas, de todo aquello que, de otra forma, la exclusiva focalización en el presente no permite ver. En un primer momento se intentará poner en evidencia la arquitectura de los cuadros de deslegitimación utilizados contra la petición de Guillotin, para analizar luego la similitud entre los registros de deslegitimación empleados en esa ocasión y aquellos que se usan actualmente contra emprendimientos peticionarios, por cuanto informan sobre la práctica peticionaria, su historicidad y sus características formales. En particular, se demostrará cómo el establecimiento de una conexión de este tipo, entre un acontecimiento pasado y prácticas actuales, permite fundamentar la idea que el objeto "petición escrita" tiene una realidad sociológica.

Las formas de deslegitimación de una iniciativa peticionaria "inédita": deslegitimar a Guillotin en vez de su petición

"No podemos daros cuenta del objeto, del motivo y del objetivo de esta petición, que no hemos tenido el tiempo de leer en su totalidad". Es con esta sorprendente frase que el abogado encargado de hablar contra la petición de los Seis Cuerpos, delante del Parlamento de París, comienza su acusación ${ }^{11}$. Se comprende mejor el significado de la afirmación si se la relaciona con la precisión que le hiciera a Guillotin el consejero Lefèvre, una vez el fallo rendido: "esa sentencia hace referencia a la forma de vuestro escrito y a su modo de difusión. En cuanto al fondo, el Parlamento - del cual yo soy aquí intérprete- no encuentra nada que decir" (Soubiran, 1962: 109). El Parlamento de París habría

11. El informe de las audiencias del Parlamento, durante las cuales el asunto de la petición Guillotin fue juzgado se encuentra en Chassin (1888: 56-78). 
ordenado a todos los notarios que habían recibido ejemplares de la Petición de los Seis Cuerpos "devolver durante el día a la escribanía de la Corte los ejemplares que cada uno de ellos podía poseer, en el estado en que estuviesen", sin, en ningún momento, haber tomado en cuenta el fondo del texto.

Esta interpretación, a la que adhiere A. Soubiran, no se encuentra en los relatos de otros biógrafos de Guillotin. J. Reveillé-Parise (Reveillé-Parise, 1851: 3) se centra en las ideas que la petición defendía, por cuanto estaban "impregnadas de un carácter de licencia e incluso de rebelión". Además, como lo recuerda C.L. Chassin (Chassin, 1888: 56sq.), en las mismas fechas el Parlamento de París condena otro folleto, "que sus autores han intentado difundir a través de procedimientos equivalentes a aquellos que acababan de inventar los Seis Cuerpos", por pretender dar al Tercer Estado un peso equivalente al del conjunto de las otras dos órdenes. Esta acusación, que justifica la nueva condena, también habría podido ser formulada en contra del proyecto de Guillotin. El contenido del texto no es entonces tan indiferente a los Consejeros como ellos lo afirman. Sin embargo, no es al contenido del texto a lo que se apunta explícitamente en la controversia.

De hecho, en las diferentes diatribas pronunciadas en contra de los peticionarios, como en los argumentos a los cuales éstos recurren para defenderse ${ }^{12}$, lo que está en cuestión no es tanto la argumentación de aquellos que la sostienen, sino el vínculo que los une a ese texto y el modo de difusión que han elegido. Dicho de otro modo, la descalificación de la petición parece generalmente pasar por la descalificación de los peticionarios y de la forma peticionaria y no por el rechazo a las exigencias formuladas en la petición, como si éstas fuesen finalmente secundarias.

El intento de deslegitimación de la petición Guillotin se desarrolla en torno a tres registros, más o menos utilizados, según las normas de publicidad a las cuales cada contexto de enunciación es sometido y también según la posición de aquellos que critican la petición: primero, un registro cognitivo, el más cercano a la crítica del texto mismo, pero que toma la forma de un cuestionamiento de las capacidades cognitivas de los peticionarios; luego, un registro intencional, el de la sospecha de las intenciones reales de los contestatarios; finalmente, un registro representativo, de marginalización de los firmantes, el de un cuestionamiento de su "tamaño". Más que reprochar a los peticionarios lo que dicen, se les reprocha no saber de qué hablan, no hacer lo que dicen hacer y/o no representar lo que dicen representar.

12. Se quiere significar de esta manera que cuando Guillotin subraya en su petición la "pureza" de su celo y cuando un detractor de la Petición sospecha de las "buenas intenciones" de los peticionarios, se trata sólo de dos formas diferentes y adaptadas a la posición de quienes las enuncian y que reconocen la "legitimidad" de un mismo cuadro de deslegitimación política de la petición escrita: el de la sospecha. 
No saben de lo que hablan: el registro cognitivo o de deslegitimación por la ignorancia

Con el decreto del 5 de julio de 1788, el Rey no está proponiendo a todos sus súbditos enviar tesis de corte político, sólo se solicitan los "sabios y personas instruidas". No es sorprendente entonces que los autores de dichos escritos, así como sus defensores, se esfuercen en realzar sus propias competencias, tanto al inscribir la Petición en el campo léxico de las Luces y de la razón, como al alabar las cualidades de su autor o señalando la "suave sensación que el pequeño libro del Sr. Guillotin" aporta al "saber"13. Los partidarios de la petición muestran los logros de su autor: el rigor de la argumentación de Guillotin así como por ejemplo su preocupación por referirse a la "última Cuenta Rendida" que certifica las Cuentas del Reino, incluso pidiendo disculpas por su audacia: Guillotin habla de sus "modestas luces".

Pero las disculpas sólo son la contraparte de los ataques recibidos en ese plano. Algunos se conforman con denunciar de manera indirecta la incompetencia o la falta de racionalidad de los peticionarios: así los autores del "Bill” se preguntan: “¿por qué no se nos permitiría charlar entre nosotros sobre asuntos políticos (así como muchos otros que no entienden nada ni concuerdan entre sí)?"14. Otros presentan los errores, de los cuales se hacen cargo algunos partidarios de la petición Guillotin, como el resultado de un problema de comprensión recíproca, un problema de "comunicación" se diría hoy en día. En esta perspectiva parece situarse un parlamentario que publica un folleto con el fin explícito de hacer más comprensible la visión del Parlamento"15. Es el "discípulo de Montesquieu" quien más lejos llega con esta forma de deslegitimación por la ignorancia. Su opúsculo se presenta como una deconstrucción del texto de Guillotin, prácticamente punto por punto: "He examinado los hechos informados en la petición del burgués de París. He probado cuán poco exactos eran" y concluye destacando una"“ignorancia" que sólo puede ser considerada culpable: "a finales del siglo XVIII, hemos tenido el dolor de ver que nada es seguro en el mundo, que las verdades más simples y las mejor demostradas pueden ser transformadas en dudas"16.

De este modo, aun cuando la crítica se refiera al argumento de los peticionarios, no está basada primero en el plano de las ideas sino en las debilidades que podrían explicar su rumbo errado. En el "mejor" de los casos se trata de una debilidad de las autoridades que no habrían entregado a los peticionarios toda la información necesaria para un juicio claro. En el "peor" de los casos se trata de una debilidad de los propios firmantes inculpados, ya sea por ignorancia, ya sea por irracionalidad y

13. Revue des principaux écrits sur les Etats-Généraux. 1789. s.l.n.d., 3 ème partie, BN-Lb397071: 66 .

14. Bill... 1788:5.

15. Sur la pétition... 1789.

16. Disciple de Montesquieu... 1789: 30, 8. 
sentimentalismo. La hipótesis más fácilmente esgrimida es aquella a la que se refiere el mismo "discípulo" cuando propone tres explicaciones para los supuestos "errores" de Guillotin: "la ignorancia, la mala fe o el interés". En definitiva, de no ser ignorantes o irracionales, los peticionarios tienen intenciones escondidas que los hacen negar la evidencia.

No hacen lo que dicen estar haciendo: el registro institucional o la deslegitimación por la sospecha

Este cuadro de deslegitimación se desarrolla en dos fases que simbolizan con claridad el tipo de argumentación adoptado por el "discípulo de Montesquieu" en su opúsculo.

En un primer momento los "errores" del autor de la petición de ciudadanos domiciliados en París son recalificados como "errores intencionales", es decir como "mentiras" o "hipocresías". Así, corrigiendo una frase de esta petición, el "discípulo" panfletario explica "esta frase es trivial, no es más que una mentira. ¿Mentir no es acaso una necesidad apremiante?"17.

Queda entonces por entender por qué los peticionarios recurren a tales procedimientos. La segunda fase del cuadro de deslegitimación institucional responde a la atribución de causalidad. Para los detractores de la petición, se trata de revelar las intenciones inconfesables que sostenían y justificaban las contra-verdades enunciadas en la petición: "luego de una larga sucesión de palabras insignificantes [con las cuales el doctor alaba la sabiduría de la Nobleza y del clero], se revela la verdadera intención"18. De esta manera, el "discípulo de Montesquieu" desarrolla un cuadro de deslegitimación según un doble registro. Se trata, por un lado, de la denuncia del interés particular que los peticionarios defienden y que intentan esconder detrás de propósitos con vocación general: los peticionarios "que son nada menos que extranjeros con especulaciones pecuniarias (...) se levantan contra las distinciones útiles [entre las órdenes]", mas no "quieren ver que en un siglo donde el dinero todo lo permite, la distinción verdaderamente humillante es la del rico y el pobre"19. Los peticionarios no se muestran finalmente muy generosos ni liberales y tampoco muy preocupados por "el bien del prójimo 20 ". Por otro, se trata del cuestionamiento de las intenciones políticas subyacentes de la petición: el "discípulo" denuncia el uso de "medios lamentables" para "abusar y buscar excitar una insurrección en contra de un orden respetable"21 y concluye finalmente que, utilizando palabras como "justicia", "conveniencia" o "razón", los firmantes "han intentado derrumbarlo y destruirlo todo ${ }^{22 " .}$

17. Disciple de Montesquieu... 1789: 18.

18. Disciple de Montesquieu... 1789: 30.

19. Disciple de Montesquieu... 1789: 24-31.

20. Disciple de Montesquieu... 1789: 54.

21. Disciple de Montesquieu... 1789: 22.

22. Disciple de Montesquieu... 1789: 38. 
Ahora bien, un mismo argumento se encuentra en casi todos los escritos de denuncia contra la petición Guillotin. Los parlamentarios concuerdan con la argumentación expuesta en un opúsculo publicado luego del veredicto ${ }^{23}$ en el cual su autor enuncia sospechas respecto a las intenciones políticas y al egoísmo de los peticionarios:

\begin{abstract}
“¿Estáis vosotros seguros que esta petición sólo ha sido hecha con buenas intenciones? ¿No veis alguna trampa escondida bajo esta tolerancia, sobre este poder dado a los notarios para recibir las firmas? (...) ¿Estamos seguros que los clamores no tienen su base en el corazón de financieros, especuladores, rentistas y pensionados, todos enemigos impenitentes de la Magistratura (...), que están siendo levantados por enemigos irreconciliables de la Nación?".
\end{abstract}

Pero también y sobre todo, las críticas "plebeyas" contra la petición Guillotin parten de una base exactamente inversa a los intentos de deslegitimación "aristocrática". Ahí donde algunos reprochan a los "burgueses parisinos" querer aliarse con el populacho para conseguir la "democracia", otros parecen temer que quieran maniobrar para convertirse en los "nuevos privilegiados", en alianza con los antiguos. Pero por más distintas que éstas sean, las críticas se basan en argumentaciones similares. Todas plantean sospechas en cuanto a las intenciones reales de los peticionarios, para luego "reducir" las intenciones políticas de los suscritos a la mera búsqueda de intereses materiales particulares. Por ejemplo, los "habitantes de Bagnolet"24 subrayan que los "Seis Cuerpos han hecho valer con todas sus fuerzas su postura en contra de los privilegios de la Nobleza, pero que teniendo fundamento nada han dicho sobre las inmunidades y regalías que nosotros os proponemos atacar", especialmente la exención de los hijos de la burguesía de la Milicia, mientras que un "médico de pueblo" 25 pregunta a los peticionarios si acaso ellos no han "estado encabezando las demandas del Pueblo sólo para impedirle hacer otras más grandes y poner con ello las pretensiones de las Ordenes privilegiadas fuera del alcance de todas las investigaciones posteriores". Los peticionarios intentan dar respuesta a estas insinuaciones, lo que parece confirmar desde su punto de vista también que es en ese cuadro de deslegitimación política que su iniciativa es más vulnerable. Los promotores de la petición Guillotin reivindican la "pureza de su celo", la transparencia de su conducta, su patriotismo, la moderación de sus propuestas o su abnegación por el interés general.

En suma, sólo uno de los cuadros de justificación peticionaria no corresponde cabalmente a los cuadros de deslegitimación que se han podido

23. Sur la pétition... 1789.

24. Sin que se pueda saber con precisión quiénes son los autores de los diversos escritos evocados, nada impide pensar que esta crítica "plebeya" contra la iniciativa Guillotin no sea la obra de un "aristócrata". Aún así, consideramos que este texto informa sobre el tipo de argumento al cual una crítica "plebeya" de la petición podía recurrir, legítimamente, en esta configuración. Bill... 1788.

25. Réponse d'un médecin de villageà la pétition du docteur G. collection Rondonneau, AN AD1 6. 
distinguir. Se trata de los argumentos con los cuales el doctor Guillotin o algunos de sus turiferarios intentan disculparlo de una acusación de la cual no se encuentran huellas directas en los textos analizados: aclaran que no quiso aprovecharse de la iniciativa para hacer avanzar los intereses de su "clase", ni menos defender sus propios intereses con el fin de construirse una reputación.

Intereses personales, intereses de "clase", intereses políticos. La denuncia de las intenciones escondidas de los promotores de la petición Guillotin tiene un corolario: el hecho que estos últimos pudiesen manipular a los firmantes, desviando ese apoyo en su propio beneficio. Es la conclusión sobre la cual desemboca naturalmente el "discípulo de Montesquieu" cuando interpela a los "Verdaderos mercaderes de París" por cuanto debieran "ver con pena que el autor de la petición haya abusado tan groseramente de su inocencia y de su candor"26. De ahí que los cuadros de deslegitimación por la sospecha sean indisociables de otra forma de desacreditar a los peticionarios (y a su petición en consecuencia): el cuestionamiento sobre su representatividad, lo que en otro contexto T. Gitlin (1980: 27sq) llama "marginalización".

No representan lo que dicen representar: el registro representativo o la deslegitimación por la marginalización

En los escritos que atacan a la petición Guillotin, el cuestionamiento de la "representatividad" de la petición arranca de cuatro posiciones. Para algunos, aquellos que utilizan la petición no pueden pretender representar a todos los que la firmaron. Para otros, no representan tampoco al grupo del cual se presentan como los defensores, el Tercer Estado o los habitantes de París. Para otros aun, sólo se representan a sí mismos, un grupo demasiado homogéneo sociológicamente como para tener algún peso: los burgueses de París. Para los últimos, finalmente, lo que representan no es pertinente en relación con aquello que está en cuestión, la convocatoria a los Estados Generales y lo que ella implica.

La crítica jurídica se forma esencialmente según el primer registro. Los parlamentarios, públicamente, cuestionan sobre todo la forma de difusión de la Petición y las dudas a las que puede inducir en cuanto a la existencia de firmantes y a la realidad de su consentimiento. Así, en su acusación, el Sr. Séguier cuestiona la "autenticidad de un acto al cual se invita a todos los Cuerpos y a todos los particulares a otorgar su adhesión". Una "autenticidad" que haría referencia a dos dimensiones. Primero, a la cuestión de la existencia de los propios firmantes cuyos nombres figuran abajo de la Petición. Es lo que ponen en duda los parlamentarios que publican un folleto al día siguiente del veredicto:

"Que se lea, si es posible, todos los nombres y que se jure que tres cuartos han tomado la pluma y firmado. ¿Sabemos acaso si no ha sido el

26. Disciple de Montesquieu... 1789: 18. 
mismo hombre el que ha firmado en todos los bufetes con nombres diferentes? ${ }^{27 \prime \prime}$.

No obstante, lo esencial de la desconfianza de los parlamentarios hacia la Petición Guillotin radica más bien en la realidad del consentimiento de los firmantes, supuestamente verdaderos: ¿no habrán sido manipulados por los promotores de la petición, no habrán firmado bajo la presión de otra persona? Se les pregunta entonces a los acusados C.N. Duclos de Fresnoy, al Sr. Perrier o al doctor Guillotin si solicitaron firmas. Pero el propio veredicto, así como el decreto del Consejo de Estado del Rey por medio del cual, poco después (el 25 de febrero de 1789), toda petición colectiva escrita es "definitivamente" prohibida, insisten sobre todo en la manipulación. La manipulación consistiría en el hecho de solicitar la adhesión de otra persona para escritos propios: el decreto de la Corte condena que requerimientos al Rey sean depositados "donde los oficiales públicos para los efectos de recibir las firmas de Ciudadanos de todas las Ordenes" y "más aún" el hecho de "solicitar sus firmas para cartas o advertencias impresas y difundidas entre el público". Por su parte, los acusados afirman que de ninguna manera activa buscaron otros adherentes a la Petición, al punto que incluso no dudan en probar su buena fe, haciendo notar las pocas firmas que recogieron para su propio ejemplar: el Sr. Perrier sólo recogió "algunas", una sola persona en el caso de C.N. Duclos de Fresnoy.

Al poner el acento en el débil número de firmantes, los peticionarios corren el riesgo de ser confrontados a otro tipo de marginalización: el cuestionamiento de su capacidad para representar al grupo que dicen representar. Se pone así en cuestión la pretensión de los peticionarios de hacerse pasar por voceros de los habitantes de París sin importar su orden, o por el contrario, del conjunto del Tercer Estado. Los opositores "aristócratas" y "plebeyos" cuestionan la capacidad de los peticionarios para representar al Tercer Estado. Cuando Guillotin adelanta en su petición que "hay dos grandes intereses en el Estado esencialmente opuestos, los privilegiados y los no privilegiados" y concluye que los representantes del Tercer Estado deben ser elegidos en aquel Orden, el "discípulo de Montesquieu" y los" "habitantes de Bagnolet" le oponen la heterogeneidad intrínseca del Tercer Estado. El primero distingue así "dos clases absolutamente diferentes por sus ocupaciones y sus intereses opuestos en casi todos los aspectos": el "alto tercio, más capitalista que agricultor, está encerrado en las ciudades. El bajo tercio (...) vive en el campo" y "no ha intervenido en esas innumerables peticiones" 28 . Los otros hacen valer que "el Tercer Estado se divide y se subdivide en una infinidad de clases, opuestas entre sí por miles de intereses diversos" y piden que los "agricultores y jornaleros de todas las especies" tengan un número de representantes proporcional a su población ${ }^{29}$.

27. Sur la pétition... 1789.

28. Disciple de Montesquieu... 1789: 54.

29. Bill ... 1788: 12 . 
El cuestionamiento de la heterogeneidad real de puntos de vista que quisiera asumir una misma petición tiene como corolario la denuncia de la relativa homogeneidad de los peticionarios, su incapacidad para obtener apoyo por parte de quienes son demasiado diferentes de ellos. Esta forma de reduccionismo se encuentra particularmente puesta en práctica cuando el grupo de peticionarios es definido por sus detractores como una categoría única, a menudo ridiculizada con un calificativo menoscabador. Para el "discípulo de Montesquieu", la petición Guillotin es "la petición de los burgueses de París", una categoría que él define distinguiéndola por una parte de la Nobleza y, por otra, de los agricultores, los no-citadinos. En cuanto a los autores del Bill, éstos estigmatizan más bien la riqueza de los partidarios de la petición Guillotin que bautizan de "Petición de los Seis Cuerpos". Las expresiones utilizadas para nombrar la petición, lejos de ser el resultado del azar, están al centro de una lucha sobre la legitimación de la acción peticionaria: entre la apelación elegida por Guillotin (la "Petición de ciudadanos domiciliados en París") y las que proponen sus detractores, lo que está en juego es el nivel de amplitud de los apoyos que puede recibir la petición, la importancia de los intereses que supone defender y, finalmente, su dimensión misma.

La forma de calificación de la petición, es decir, una de las tantas formas de descalificación, implica una última forma de "marginalización" de los peticionarios. No solamente se les reprocha representar a un medio sociológicamente muy homogéneo, sino que además se pone en duda que ese medio corresponda al público realmente identificado con los problemas en juego. Así, por ejemplo y de la manera más radical, en el "Bill de los habitantes de Bagnolet" se asocia la legitimidad de las demandas a la ilegitimidad relativa de los peticionarios, quienes no constituirían más que una casta privilegiada de la población y no merecerían por lo tanto, como los habitantes del campo, ser escuchados por el Rey:

\footnotetext{
"¡Por qué no haríamos nosotros, a la manera de los señores de los Seis Cuerpos, una petición en materia de Bill! ¿No somos nosotros, al igual que ellos, hijos de nuestro buen Rey?" (...) ¿[no debería éste más bien marcar una preferencia] hacia nuestros pobres y laboriosos campesinos en lugar de esos grandes Burgueses y Mercaderes de la Capital?"30.
}

Lo que está en cuestión, no es solamente que la petición sólo represente a una parte del Tercer Estado, sino, sobre todo, que ésta no represente a su buena parte, de la cual los Estados Generales debieran efectivamente considerar los intereses.

Así, al escuchar o los opositores de la petición Guillotin, ésta no sufriría tanto de su argumentación interna, ni de sus demandas, sino de un conjunto de otras taras conexas: la irracionalidad y la ignorancia de sus autores, sus intenciones escondidas, la preocupación por defender intereses personales, materiales o políticos y su falta de representatividad.

30. Bill... 1788: 3-5. 
En consecuencia, se trata de una acción peticionaria cuyo contenido no sería presentado como la principal preocupación "pública" de sus detractores. Una acción peticionaria cuestionada por su modo de difusión y sus segundas intenciones eventuales, más que por su contenido explícito. Una acción peticionaria a propósito de la cual, finalmente, la pregunta sobre el número de firmantes no sería casi nunca planteada. Se podría pensar que los cuadros-formas de deslegitimación forjados por los opositores de la petición Guillotin son, en este punto, específicos de su contexto político e histórico, a la pregunta planteada en ese contexto, a los apremios que se imponían en ese entonces a los actores de tal configuración, los cuales sólo serían eficaces en relación a ese episodio y que, por lo tanto, su análisis no sería de gran ayuda para quienes quisieran comprender las formas contemporáneas de deslegitimación de la petición escrita. ¿Debe entonces concluirse que los cuadros de deslegitimación utilizados para detenerla no habrían sobrevivido al cambio de contexto?

\section{Las enseñanzas de una conexión histórica incongruente}

Inversamente, el examen de iniciativas peticionarias más contemporáneas, la forma en la cual sus destinatarios han podido intentar deslegitimarlas, tiende a mostrar que entre los cuadros de deslegitimación empleados en contra de la petición Guillotin y aquellos que algunos utilizan actualmente contra las acciones peticionarias, no hay solución de continuidad.

Para tomar un ejemplo entre muchos otros, a propósito del movimiento peticionario iniciado en Francia en febrero de 1997 por cineastas contra un proyecto de ley que apuntaba a limitar la inmigración, cuando un diputado francés de centroderecha, P. A. Wiltzer, estima que "nuestro país pasa por cartesiano. Se podría dudar de ello viendo a numerosos artistas e intelectuales enardecerse a propósito de la inmigración clandestina. ¡Al punto de rechazar todo control de la inmigración! ¡Al punto de llamar a desobedecer las leyes!" (Le Républicain-Journal de l'Essonne, 27/2-5/3/1997), no se está conformando con expresar un simple desacuerdo político, retomando "objetivamente" el punto de vista de los peticionarios para oponerse, él propone una interpretación que busca caricaturizar y deslegitimar la petición. Esto es, primero, restringiendo el grupo de firmantes a "numerosos artistas e intelectuales", cuando muchos de los que habían firmado rechazaban esta etiqueta. Luego, resumiendo sus demandas a un rechazo de todo control de la inmigración, cuando varios de los firmantes pretendían que predominara una concepción estrictamente inversa. Finalmente, oponiendo el lado "cartesiano" de Francia a los sentimientos de los firmantes que "se enardecen", cuando, según algunos de los partidarios de la petición, es el gobierno el que trata de jugar con los sentimientos. 
En este simple episodio contemporáneo, se encuentran los dos rasgos que se podrían haber considerado como específicos de la petición Guillotin de 1788. Primero, el hecho que la crítica busque atacar a los propios peticionarios, la relación que éstos tienen con el texto, sus intenciones ocultas más que la tónica de sus reivindicaciones. En segundo lugar, la idea que los detractores de una petición puedan jugar con un triple registro de descalificación. Un registro cognitivo, el de la desinformación, cuando el diputado cuestiona la ignorancia de los peticionarios, la irracionalidad de éstos, los efectos supuestamente no intencionales que podría tener su acción. Un registro intencional, el de la sospecha, cuando desconfía de las "verdaderas" motivaciones de los peticionarios como escondidas detrás de lo que los peticionarios muestran: el abandono de todo control de la inmigración detrás de la lucha contra un artículo de un proyecto de ley. Un registro representativo, finalmente, el de la marginalización, cuando el diputado cuestiona los amplios apoyos de los cuales disponen las reivindicaciones así desarrolladas, cuando reduce esos apoyos a una categoría homogénea y, a sus ojos, menoscabadora, los "artistas e intelectuales".

Con esta referencia, no se trata de concluir por una vuelta retórica artificial, que todo ya estaba en la petición Guillotin y en los debates que ella pudo suscitar, sino simplemente de preguntarse lo que el establecimiento de una conexión audaz entre el pasado y el presente nos puede enseñar sobre la forma peticionara, lo que ese tipo de descentramiento por la historia puede enseñarnos sobre esta forma de acción protestataria y sus modos de deslegitimación. Ahora bien, lo que se obtiene, es que la forma peticionaria, más allá de las diferentes formas de apropiación por la cual es esencialmente caracterizada como objeto, parece ser siempre vulnerable a un mismo tipo de argumentación y, es así porque está esencialmente caracterizada por un conjunto de rasgos intangibles.

\section{Configuración peticionaria y disponibilidad de los cuadros de deslegitimación}

D. Trom (1999: 40-41), estudiando las situaciones de conflicto en situaciones de esta naturaleza, concluyó en la existencia de una "arquitectura característica" en ese tipo de controversia, constituida por un conjunto limitado de "motivos" aceptables mediante los cuales los militantes podían justificar su acción: son siempre el mismo tipo de argumentos que se encuentran en tales conflictos.

La similitud de los registros de deslegitimación empleados contra la petición escrita, en contextos históricos diferentes, conduce a preguntarse si se podría decir lo mismo de los cuadros de deslegitimación utilizados en contra de la forma peticionaria. Parece, efectivamente, que esta forma de acción colectiva ha sido vulnerada frente a una "arquitectura" deslegitimadora, que fue relativamente uniforme durante un largo período. Parece ser así, incluso aunque no se activen los mismos cuadros de deslegitimación: éstos son distintos dependiendo de 
los diferentes contextos de la petición escrita, de la posición de quienes la critican y del desarrollo de los conflictos. Cualquier cuadro de deslegitimación no es posible en todos los tipos de configuración peticionaria; sin embargo en cualquier tipo de configuración peticionaria los opositores pueden utilizar un repertorio de registros de deslegitimación relativamente restringido.

Así, por un lado, se ha visto que los parlamentarios y los panfletarios "aristocráticos" o "plebeyos" no movilizan los mismos cuadros contra la petición Guillotin. Mientras algunos enfatizan las intenciones políticas escondidas de los peticionarios e insisten en la manipulación de la cual podrían haber sido sujeto los firmantes, otros subrayan más bien la incompetencia de los autores, su egoísmo y su débil representatividad respecto del grupo al cual dicen pertenecer y cuyos intereses deberían efectivamente primar. Se percibe así cómo la disponibilidad de cada uno de los cuadros de deslegitimación varía en función de las dificultades que cada opositor debe enfrentar, según su posición en el campo del poder. Para los parlamentarios es difícil desacreditar a los peticionarios denunciando sus privilegios, sin embargo ese registro es casi evidente para el supuesto cultivador.

Se podría igualmente mostrar que los diferentes tipos de iniciativas peticionarias -según su objeto, según sus apoyos, según su modo de difusión, según el momento del conflicto donde intervienen, según el contexto de enunciación en el cual han aparecido- son más o menos vulnerables a los diferentes cuadros de deslegitimación política, en la medida que el uso de un cuadro de deslegitimación inadaptado a la petición, que tuviese por función denigrarla, podría volverse en contra del acusador. Se comprende así el porqué del apoyo que los Seis Cuerpos le dan a la petición Guillotin, donde la opción de firmar la petición en los bufetes de los notarios, sin que éstos hayan tenido que autentificar las firmas, habría podido facilitar las acusaciones, que hubiesen podido ser formuladas en su contra, sobre intereses particulares o sobre la falsificación de firmas.

Pero sobre todo, el giro por la historia permite subrayar la evolución diacrónica de la disponibilidad de los diferentes cuadros de deslegitimación política de la petición escrita. Cuando los defensores del Parlamento de París explican que "seguramente, nadie esperaba todas las firmas que se dieron, nadie esperaba nada cuando todos los Parisinos, uno después de otro, dieron la suya", se comprende que uno de los cuadros de deslegitimación de la petición escrita más utilizado en la actualidad, es decir, la denuncia de la debilidad relativa del número de firmantes, no es ni considerado ni considerable en función de las normas de legitimidad política que prevalecían entonces. Primero, porque el número no es visto como un elemento de justificación posible. Luego, ya que por el contrario, algunas tecnologías políticas que facilitan hoy en día esta forma de "marginalización" no eran operativas: se puede pensar en las encuestas o en el referéndum. En cambio, la cuestión de la autenticidad de las firmas, que consti- 
tuirá uno de los mayores sesgos de deslegitimación de las iniciativas peticionarias en los orígenes de esta forma de acción, al punto de ser el objeto de numerosos debates parlamentarios sobre los medios legales para autentificar las iniciales, tiende a ser actualmente un cuadro de deslegitimación marginal. Finalmente, a partir de los trabajos de E. Neveu (1994), se puede formular la hipótesis que la utilización del registro cognitivo de deslegitimación a nombre de un problema de comunicación -“ustedes protestan porque no han entendido, porque nos hemos expresado mal"se ha desarrollado en una sociedad marcada por la omnipresencia de los medios de comunicación. El registro de la sospecha parece ser el único en no haber sufrido mayores transformaciones durante el período: la tentación de buscar cuáles son los intereses que defienden realmente los peticionarios detrás de las demandas explícitas que éstos formulan parece igualmente presente hoy en día que en la época de Guillotin.

En consecuencia, se podría representar la arquitectura de los cuadros de deslegitimación de la petición escrita desde dos ejes: uno que tomaría en cuenta la evolución diacrónica de los cuadros de deslegitimación de la petición escrita en función de las tecnologías políticas disponibles, de las normas de legitimidad política prevalecientes y de los repertorios vigentes de acción peticionaria; otro en el que figuraría la disponibilidad sincrónica diferencial de ese cuadro de deslegitimación, según los tipos de petición contra los cuales se dirige y según la posición que el detractor ocupe en el campo del poder.

En cada una de esas configuraciones, los opositores a una petición parecen usar los mismos registros de deslegitimación. Pero esta demostración no deja de plantear interrogantes. ¿Cómo explicar que una forma de acción, pudiendo ser investida por actores tan diversos en contextos igualmente diversos y por causas también distintas, continúe siendo vulnerable frente a un repertorio de cuadros de deslegitimación finalmente restringido? Se podría intentar invocar el peso del pasado. Sin embargo, si se acepta la excepción, que parece ser la crítica de derecha contra las peticiones denominadas de "intelectuales", no se percibe realmente qué tipos de soporte podrían facilitar la transmisión de registros de deslegitimación de una configuración peticionaria a otra. En consecuencia, se debe más bien imputar la relativa perennidad de los registros de deslegitimación a ciertas características persistentes de la forma peticionaria.

\section{Las características formales de la práctica peticionaria}

Ahora bien, analizando el episodio de la petición Guillotin, se vislumbran tres características: primero, la fuerza del vínculo que parece acercar a cada peticionario a la petición que ha firmado o pide firmar; luego, la particular vulnerabilidad de una forma de acción cuya legitimidad puede ser cuestionada con argumentos tanto más heterogéneos cuanto que ella se encuentra en posición de "doble vínculo" (double-bind); final- 
mente y, quizás sobre todo, la ilegitimidad esencial que parece sufrir ese modo de acción respecto a los principios de la democracia representativa.

\section{La firma o la fuerza de un vínculo contractual}

Si las críticas dirigidas contra una petición son indisociables, ante todo las críticas dirigidas contra aquellos que la han lanzado o firmado, es quizás porque cada firmante está más íntimamente ligado al acto peticionario que comete que a otros modos de acción. Esta hipótesis va, por supuesto, contra todo lo que pudo haber sido dicho sobre la petición escrita, en cuanto a constituir un compromiso mínimo, sin riesgo.

Sin embargo, el ejemplo de Guillotin muestra que iniciar una petición puede marcar por siempre la trayectoria de un individuo. Creyendo en sus biógrafos, en parte, Guillotin debe al papel que jugó en la "Petición de ciudadanos domiciliados en París" la función de "piedra angular" frente a una cierta prensa durante su mandato parlamentario $\mathrm{y}$, sobre todo, más específicamente, el funesto privilegio de no haber podido "desligar su nombre de su invención" (retomando la expresión de Victor $\left.\mathrm{Hugo}^{31}\right)$. Por cierto, no se podría ver en este ejemplo más que un caso particular, explicable en referencia al impacto de esta petición, por la posición de iniciador que en ella ocupa Guillotin y por el plazo relativamente corto entre la petición y los sarcasmos a los que estuvo expuesto el doctor.

No obstante, ciertas características de la petición escrita participan en esta asimilación del peticionario a su "petición". Efectivamente, el acto peticionario tiene esa particularidad entre las otras formas de participación política: tiene la reputación de dejar la huella escrita de un compromiso identificado con un nombre, una firma y, muchas veces, una dirección. En la mayoría de los casos, con la práctica peticionaria no es posible quedarse en la frontera, del interior o del exterior. No se puede tampoco, fácilmente, evocar el efecto de inercia imputable al acto colectivo, ya que la firma individualiza el compromiso. Por último, contrariamente a otras formas de movilización, la huella que deja la petición es concreta y duradera.

Así, la firma de la petición puede comprometer, aún más que otros actos de movilización que no son objeto de una objetivación tan clara y durable. Todo lleva a aproximar la situación peticionaria a una situación contractual: la fecha, el nombre y el apellido, la dirección y, sobre todo, la firma que tiende a transformar el documento escrito en acto jurídico. Además, a través de su firma, el peticionario atribuye a la petición todas las propiedades con que se la asocia en otros campos. En cambio, son las

31. "Hay hombres infelices. Cristóbal Colón no puede atar su nombre a su descubrimiento; Guillotin no puede desligar el suyo de su invento" (Hugo, Victor. 1976, Littérature et philosophie mêlées. Paris: Klincksieck). 
propiedades de la petición, la manera en la que es percibida, que pueden reflejarse en el conjunto de las trayectorias biográficas de los firmantes: firmar una petición no es solamente un acto puntual; también es aceptar la idea de ser considerado, quizás incluso largo tiempo después, como alguien que ha firmado una petición.

Se percibe entonces cómo este fuerte vínculo entre la identidad del firmante y la petición que firma -en la cual se encuentra por ejemplo el grado de solemnidad con la que ciertos firmantes envuelven su compromiso $^{32}$ - puede repercutir en los modos de legitimación de la petición. Atacar una petición es empañar la reputación de aquellos que la iniciaron o que la firmaron. Atacar a quienes la iniciaron o que la firmaron es empañar la reputación de la propia petición.

\section{La forma peticionaria bajo la influencia de "dobles vínculos"}

Ahora bien, ciertas características de la dinámica peticionaria parecen poner a los peticionarios en una posición particularmente vulnerable frente a la crítica.

La ruptura esencial entre los que lanzan la petición y los que la firman autoriza a los opositores a cuestionar el vínculo entre unos y otros. Si ese vínculo es demasiado evidente, la homogeneidad de los firmantes puede ser cuestionada, como cuando los detractores de la petición Guillotin restringieron la identidad de sus partidarios sólo a los burgueses parisinos. Si el vínculo es demasiado sutil, por el contrario, es su heterogeneidad y el derecho de vocería de los firmantes, de hablar en su nombre, los que pueden ser cuestionados, como cuando se señalaba la diversidad de intereses de un Tercer Estado que la petición Guillotin no podía representar por sí sola.

Segundo, la relación de un conjunto de reivindicaciones objetivadas en un texto y un conjunto de apoyos objetivados en una lista de firmantes permite siempre a los detractores de una petición cuestionar el vínculo entre firmantes y el interés defendido. Si ese vínculo es demasiado directo, la petición puede ser remitida a sus intereses particulares, como lo hacen los "habitantes de Bagnolet" respecto de aquellos que olvidan atacar los privilegios de los "burgueses". Por el contrario, si ese vínculo es demasiado distendido, si los peticionarios no parecen estar directamente afectados por la causa que eligieron defender, pueden ser remitidos a sus propios asuntos en nombre de lo que podría llamarse el efecto "NIMBY": ustedes no tienen legitimidad para protestar ya que "it is not in your back yard". Los opositores de la petición Guillotin, por ejemplo, dan a entender que es la opinión de otras clases de la población, las

32. Evidentemente, aun cuando convenga matizar este argumento, anotando que, para ciertas personas, en las mismas circunstancias, la firma de una petición es un acto rutinario, fortuito. 
clases realmente útiles, que debe ser tomada en cuenta para determinar el modo de formación de los Estados Generales.

Si se agrega que la denuncia de la debilidad relativa del número de firmantes puede también ofrecer, a los eventuales opositores de una iniciativa peticionaria, oportunidades contradictorias pero complementarias para cuestionarla -señalando el pequeño número de firmantes si ése es el caso, variando el cuadro de referencia si la movilización parece relativamente importante-, se comprende que la forma peticionaria, en su fundamento mismo, pueda ser sometida a un conjunto de órdenes expresas y paradójicas que la vulneran frente a la deslegitimación, que la mayoría de las veces sus detractores puedan eximirse de atacar el fondo de la argumentación de los peticionarios.

Además, frente a una petición iniciada por firmantes plenamente informados sobre el asunto en juego, con intenciones perfectamente claras y de representatividad incontestable, los opositores no están totalmente desarmados. No solamente porque uno de los aspectos cruciales de la confrontación entre los peticionarios y sus detractores es determinar si dicha petición es efectivamente inatacable sobre esos puntos. Sino también y sobre todo, porque siempre se puede oponer a la supuesta legitimidad peticionaria otra forma de legitimidad, la que deriva de un régimen representativo y que, en principio, rechaza la idea de que una opinión peticionaria pueda interferir en el posicionamiento de los representantes.

\section{La ilegitimidad de principio de la petición escrita}

Algunos de sus opositores, principalmente los parlamentarios, no sólo cuestionan las modalidades de la petición Guillotin, sino el principio mismo de la petición escrita como modo de agregación de apoyos individuales para intervenir en el espacio público.

\footnotetext{
“La réplica encuentra su fundamento en un doble argumento. Se trata primero del cuestionamiento de lo que podría convertir la petición escrita en un medio de presión sobre el poder real: a saber, la importancia del número. Afirmar que "el Parlamento, por sus defensores, dijo a los parisinos que si no se les engañaba en las intenciones, se les engañaba en los hechos, haciéndoles firmar, como si fuese su voluntad, un escrito que era la manifestación del deseo de un sólo hombre 33 o, afirmar que "[el Parlamento] dijo y declaró que cien hombres, que mil hombres que se habían desplazado en diferente número, uno después de otro, en veinte bufetes diferentes, para firmar el mismo escrito, nunca podrían hacer pasar este escrito por el acuerdo unánime de cien, de mil" 34 , es sobrentender que lo problemático de esta petición es, ante todo, el hecho que se proponga a individuos firmar un texto en cuya redacción no han participado. En otras palabras, lo que está en cuestión es precisamente lo que define a la
}

33. Es el autor de este trabajo quien destaca.

34. Sur la Pétition... 1789. 
petición escrita en su modalidad sociológica moderna. Ciertamente, se podría suponer que esta prevención se ajusta a un período pre-revolucionario. Sin embargo, se ha podido demostrar que se encuentra la huella de esta desconfianza tanto en el período pre-revolucionario como hoy en día, si se consideran las normas implícitas sobre las cuales se basa la recepción parlamentaria de las peticiones" (Contamin, 1998).

Lo mismo se desprende del segundo argumento en nombre del cual las autoridades reales dicen rechazar el principio mismo de la petición escrita; el de la necesaria y total subordinación de las prácticas peticionarias al orden institucional. A la tentación que considera que la petición Guillotin, apoyada por los Seis Cuerpos y por las firmas de particulares, podría ser más que una simple súplica, un simple llamado a la bondad del Rey; el Consejo de Estado del Rey responde con su decreto del 25 de febrero de 1789 condenando toda veleidad que "modifique el orden establecido y que contraríe el deseo general de la nación". Una norma a la cual los peticionarios se sintieron, por lo demás, obligados a suscribir, multiplicando en el cuerpo de la petición y luego en sus testimonios, juramentos de fidelidad a la persona del Rey y al orden establecido. Esta norma de subordinación de la petición escrita al orden institucional y representativo ha sobrevivido a los cambios del orden institucional y continúa siendo, desde entonces, la última manera de cuestionar la legitimidad de una acción peticionaria, sin tener que refutar lo bien fundadas de las reivindicaciones que ésta podría apoyar. Eso es lo que simboliza el desafío que A. Perrin, presidente del comité "Chirac, 14 años" lanza a los peticionarios contra el proyecto de ley Debré durante un foro televisado (L'Hebdo, Canal +, 22/2/1997):

"les propongo una sola cosa, ustedes, y todos los cineastas, todos los peticionarios. (...) En un año más hay elecciones legislativas, preséntense. (...) $\mathrm{Y}$, una vez que sean elegidos, podrán modificar la ley. Pero, por el momento, respeten las instituciones, respeten a las personas que han sido elegidas".

Poco importa el contenido de las peticiones, poco importan las modalidades de la petición escrita, por esencia, la forma peticionaria sólo puede ser ilegítima ya que ella contrarresta el único modo de acceso legítimo a la agenda política, el cedazo representativo.

Se podría, claro está, rebatir que este argumento puede ser fácilmente contrarrestado en su radicalidad. Pero ello significaría olvidar que no se intenta aquí evaluar la eficacia de los cuadros de deslegitimación de la petición escrita, sino solamente delimitar su arquitectura, su evolución, sus modalidades y recursos. Finalmente, el Consejo de Estado del Rey decidirá el 27 de diciembre de 1788 retomar ciertas medidas preconizadas por la petición Guillotin -el número de diputados del Tercer Estado será igual al de los dos otros -y refutar otras- habrá 1.000 diputados en los Estados Generales y no 1.200. Por último, el gobierno de Juppé volverá a revisar el artículo 1 del proyecto de ley Debré. Pero a falta de un estudio de impacto comparable al que W. Gamson (1992) pudo efectuar sobre otro objeto, nadie sabrá qué rol habrá desempeñado en esta evolu- 
ción, en cada caso, la lucha por la interpretación entre cuadros de deslegitimación y cuadros de justificación de la petición escrita.

¿En qué medida la Petición Guillotin y las formas de deslegitimación a las cuales ella ha podido ser confrontada han hecho "jurisprudencia"? Sin duda menos de lo que se podría pensar si se asocia a la idea de "jurisprudencia" la de un precedente al cual los actores harían explícitamente referencia para justificar su acción. Pero sin duda más de lo que se podría haber pensado al principio de esta investigación. Pensamos haber mostrado aquí, efectivamente, que la arquitectura general de los cuadros de deslegitimación que son hoy en día utilizados en Francia en contra de acciones peticionarias - un triple registro de denunciación de orden cognitivo, intencional y representativo- también está comprendida en las reacciones suscitadas por la petición Guillotin. Queda entonces por entender cómo ese repertorio pudo perpetuarse en ausencia de soportes que faciliten su transmisión de manera general.

Es a esta pregunta a la cual permite responder parcialmente el giro por la historia y, particularmente, a través de este "caso constitutivo" que es la petición Guillotin y las polémicas que ésta suscitó, en una época cuando los registros de justificación y de deslegitimación no eran lo suficientemente rutinarios como para no ser plenamente explícitos. Es esencialmente la cristalización de una forma de acción dotada de características singulares como lo es la petición -el vínculo "contractual" que crea entre cada firmante y su compromiso, la particular vulnerabilidad que sus modalidades de funcionamiento le significan frente a los cuadros de deslegitimación contradictorios y complementarios o la ilegitimidad principal a la que se la vincula en un régimen representativo- lo que explica la relativa permanencia de registros de denuncia contra la petición escrita.

Sin embargo, sólo llevando a cabo el mismo tipo de investigación sobre otras formas de acción pública ciudadana se podrá determinar en qué medida esas formas de deslegitimación son o no propias de la práctica peticionaria y, así, concluir definitivamente que la hipótesis según la cual la petición escrita responde a un modelo relativamente uniforme y específico puede ser validada.

En todo caso, no habría que inferir la ausencia de evolución histórica de esos modos de deslegitimación. Por el contrario, lo que el "rodeo" por el presente de la petición escrita demuestra, es que al interior de esta arquitectura relativamente estable, los registros de deslegitimación de la petición escrita han sufrido importantes transformaciones, ligadas en particular a la evolución de normas de legitimidad política y a la aparición de nuevas tecnologías políticas. En ese sentido, se puede decir que, si el 
estudio del ejemplo histórico de la petición permite actualizar aquello que en su uso contemporáneo se ha transformado en algo tan evidente que se olvida que es actual -la vulnerabilidad de esta práctica por ejemplo-, el estudio del presente de la "petición escrita", en cuanto a él, permite una vuelta a lo socio-histórico en nombre de lo que D. Trom (2003) llama "inducción triangular", permite asir lo que se podría desdeñar porque "no está todavía" presente: la ausencia de la "importancia del número" (De Nardo, 1985), en circunstancias imprevistas. Es sobre esta provocativa apología de la fecundidad heurística y de una utilización heterodoxa de la historia que se podría terminar, concluyendo que si se pueden comprender mejor las peticiones contra la pena de muerte desde Guillotin, también se puede comprender mejor a Guillotin desde las peticiones contra la pena de muerte.

\section{Fuentes sobre la petición Guillotin}

Bill des habitants de Bagnolet, Charonne et autres lieux, pour servir de suite à la Pétition des six corps. 1788. s.l.n.d., BN- Lb39-695.

Chassin, Charles-Louis. 1888. Les élections et les cahiers de Paris en 1789. tome 1. Paris: Maison Quantin.

Disciple de Montesquieu à MM. les députés aux Etats-Généraux ou Supplément à la pétition des bourgeois de Paris...1789. s.1.n.d., BN-Lb39-1384.

Entretien curieux entre Guillaume Lefranc, bourgeois de Paris qui a signé la pétition du docteur Guillotin, et Hercule de Sottancourt, duc de Sottenville, marquis de MontreOrgueil et de Sot-Partout... Dédié aux bons patriotes. 1789. Rennes: Imprimerie du Patriotisme, BN-Lb39-1071.

Pétition des citoyens domiciliés à Paris, résultat du Conseil d'Etat du roi, et très humble adresse de remercîment présentée au roi par les six corps de la ville de Paris. 1789. s.1., BN-Lb39-6789.

Porchon de Bonval. 1789. Lettre aux électeurs du Tiers-Etat de Paris en faveur de M.Guillotin, victime d'une campagne de calomnies. s.l.n.d., BN-Lb39-1521.

Réponse d'un médecin de village à la pétition du docteur G. collection Rondonneau, AN AD1 6.

Revue des principaux écrits sur les Etats-Généraux. 1789. s.l.n.d., 3 ${ }^{\text {ra }}$ parte, BNLb39-7071.

Sur la Pétition proposée aux Parisiens. 1789. s.l.n.d., BN-Lb39-848.

\section{Bibliografía sobre el doctor Guillotin}

Cherreau, Achille. 1870. Guillotin et la guillotine. París: Aux bureaux de l’Union médicale.

Guerin, Edmond-Jean. 1908. Le docteur Guillotin. La Rochelle: Imprenta de N. Texier et fils.

Quentin-Bauchart, Pierre. 1905. Le Docteur Guillotin et la guillotine. París: Ediciones de la Nouvelle Revue. 
Reveillé-Parise, Joseph. 1851. Etude biographique. Guillotin (Joseph-Ignace). Extracto del Moniteur de 25 febrero y 10 de marzo 1851.

Soubiran, André. 1962. Ce bon Docteur Guillotin et sa "simple mécanique". París: Libreria Académica Perrin.

\section{Bibliografía}

Contamin, Jean-Gabriel. 1998. "La réception parlementaire d'une pratique "périphérique": le droit de pétition entre réfraction et réflexion". En E.Darras (dir.), La politique ailleurs. Paris: PUF, 39-71.

Contamin, Jean-Gabriel. 2001. Contribution à une sociologie des usages pluriels des formes de mobilisation: l'exemple de la pétition en France. Thèse: Université Paris I.

Contamin Jean-Gabriel. 2003. “De la fécondité épistémologique d'un rapprochement historique incongru: la pétition Guillotin et ce qu'elle enseigne sur une forme d'action publique citoyenne". En Pascale Laborier et Danny Trom (dir.), Historicités de l'action publique. Paris, PUF, CURAPP: 392-418.

De Nardo, James. 1985. Power in Numbers. The Political Strategy of Protest and Rebellion. Princeton: Princeton University Press.

Gamson, William A. 1992. Talking Politics. Cambridge: Cambridge University Press.

Gitlin, Todd. 1980. The Whole World is Watching. Mass Media in the Making and the Unmaking of the New Left. Berkeley y Los Angeles: University of California Press.

Kitschelt, Herbert P. 1986. "Political Opportunity Structures and Political Protest: Anti-Nuclear Movements in Four Democracies". British Journal of Political Science 16: 57-85.

Maza Sarah. 1997. Vies privées, affaires publiques. Les causes célèbres de la France pré-révolutionnaire. Paris: Fayard.

McAdam, Doug et Rucht Dieter. 1993. “The Cross-National Diffusion of Movement Ideas". Annals of the American Academy of Political and Social Science 528: 56-74.

Neveu, Erik. 1994. Une société de communication?. Paris: Montchrestien.

Offerlé, Michel. 1990. "Descendre dans la rue: de la 'journée' à la 'manifestation'". En P. Favre (dir.), La manifestation. Paris: Presses de Sciences Po: 90-122.

Tilly, Charles. 1978. From Mobilization to Revolution. Londres: Addison-Wesley Publishing Company.

Trom, Danny. 1999. “De la réfutation de l'effet NIMBY considéré comme une pratique militante". Revue française de science politique 49 (1): 31-50.

Trom, Danny. 2003. "Situationnisme et historicité de l'action. Une approche par induction triangulaire". En Laborier, Pascale y Trom, Danny (dir.): 463-483.

Zaret, David. 1996. "Petitions and the "Invention" of Public Opinion in the English Revolution". American Journal of Sociology 101 (6). 